\title{
El bazo errante asociado con vólvulo gástrico de tipo organoaxial
}

\author{
The wandering spleen associated with organoaxial gastric volvulus
}

Rachid Bouchentouf ${ }^{1}$

Varón de 17 años de edad sin antecedentes de interés que acude a Urgencias por dolor abdominal de $24 \mathrm{~h}$ de evolución asociado con vómitos y disnea. Al examen físico se encontró abdomen doloroso con masa epigástrica. La ecografía abdominal mostró la ausencia del bazo en su posición normal.

La tomografía computarizada abdominal mostró un bazo errante asociado con vólvulo gástrico (Figura 1).

El paciente requirió un tratamiento quirúrgico de emergencia, por laparotomía que confirmó el diagnóstico de vólvulo gástrico asociado a un bazo errante (Figura 2).

El tratamiento consistió en la detorsión y en la gastropexia.

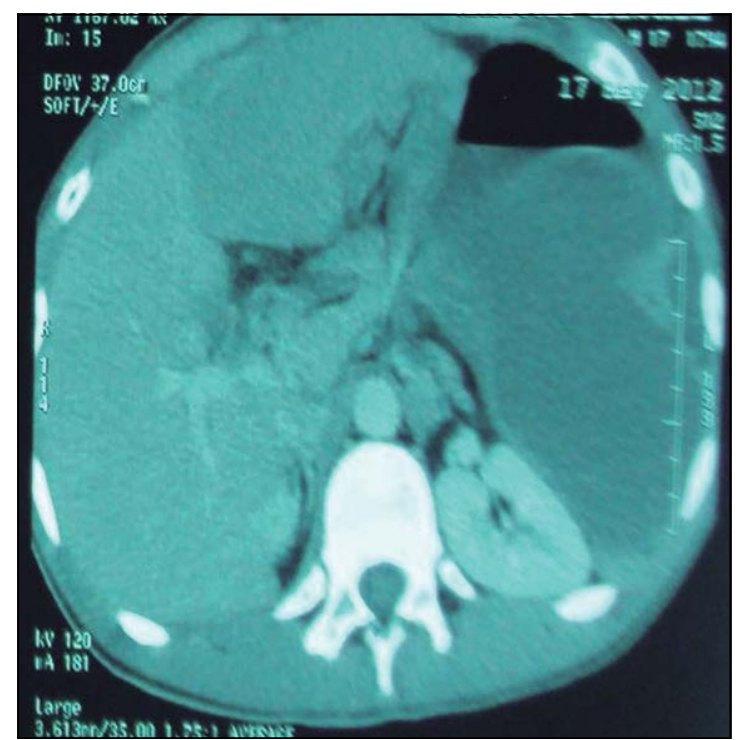

Figura 1. TC abdomen corte axial objetiva bazo errante y vólvulo gástrico.
El vólvulo gástrico es una entidad clínica muy rara, originada por el giro del estómago sobre su mismo eje. Aproximadamente el 70\% de los vólvulos son órgano-axiales y la mayoría son secundarios y de presentación aguda.

Los factores predisponentes más frecuentes son la hernia al hiato para esofágica, hernias diafragmáticas congénitas, bridas, adherencias, o secuela tardía de trauma torácico o abdominal.

La tomografía de abdomen aparece como el estudio más sensible para su diagnóstico.

El tratamiento de elección del vólvulo gástrico consiste en la detorsión y gastropexia, además del tratamiento del defecto herniario, si este existe.

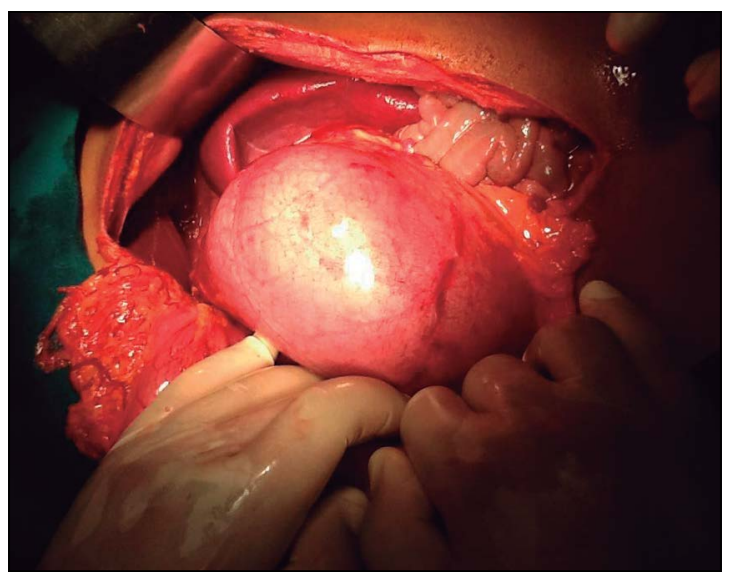

Figura 2. Imagen intraoperatoria de vólvulo gástrico.
${ }^{1}$ Hospital Militar Avicena, Marrakech, Marruecos.

Recibido el 20 de febrero de 2020 y aceptado para publicación el 5 de marzo de 2020 .

Correspondencia a: Dr. Rachid Bouchentouf rachidbouchentouf513@ gmail.com 


\section{Responsabilidades éticas}

Protección de personas y animales. Los autores declaran que para esta investigación no se han realizado experimentos en seres humanos ni en animales.
Confidencialidad de los datos. Los autores declaran que en este artículo no aparecen datos de pacientes.

Conflictos de interés: no hay.

\section{Bibliografía}

1. Faridi M, Kumar A, Inam L, Shahid R. Wandering spleen a diagnosis challenge: case report and review of literature. Malays J Med Sci 2014;21:57-60.
2. Matsushima K, Kayo M, Hachiman H, Gushimiyagi M. Laparoscopic repair of gastric volvulus associated with wandering spleen in an adult: report of case. Surg Today 2006; 36:843-5.

3. François Fiquet $\mathrm{C}$, BelouadahM,
Chauvet P, Lefebvre F, Lefort G, Poli-Merol ML. Laparoscopic gastropexy for the treatment of gastric volvulus associated with wandering spleen. $\mathrm{J}$ Laparoendosc Adv Surg Tech A. 2009;19 supp 1: S 137-9. 